between $22+6$ weeks and 30 weeks gestation. Babies discharged on home oxygen were ventilated longer (Mean=25.1 days vs 11.4 days) and were discharged a month after the comparison group (mean discharge gestation 43.9 weeks vs 39 weeks). Babies discharged with home oxygen were smaller at birth ( 25 th centile vs 43 rd centile, $p<0.05$ ), but there was no statistical significant difference in their weight centiles from 28 days to 2 years corrected. Both groups show poor growth in the first 28 days on NICU but they regained their birth centile by 4 months corrected. There was no statistical significance between the groups in the number of babies needing at least one Accident and Emergency (A and E) attendance or in-patient admission in the first year. $\mathrm{A}$ and $\mathrm{E}$ attendances were relatively common but only half resulted in admissions and very few required PICU admission $(n=6)$ in the first year. Conclusion Although babies on home oxygen were smaller and spent a longer period of time on the ventilator, their weight were similar to their preterm peers from 28 days old with catch up growth by 4 months corrected. Home oxygen requirement did not appear to additionally impact upon the A and $\mathrm{E}$ attendances, but the frequency of attendance suggests that improving parent education and enhancing community support for discharged preterm infants might reduce the burden on acute paediatric hospital services.

\section{G207(P) HYPERNATREMIA IN EARLY NEONATAL LIFE- CAN IT BE PHYSIOLOGICAL?}

I Ahmad, A Ahmed, SA Dar, JI Bhat, SW Ali, BA Charoo, QI Ahmad, MA Bhat. Department of Neonatology, Sheri Kashmir Institute of Medical Sciences, Srinagar, India

\subsection{6/archdischild-2018-rcpch.202}

Aims To monitor serum sodium levels (in $\mathrm{mEq} / \mathrm{l}$ ) in healthy term/near-term infants in early neonatal period. To identify risk factors for hypernatremic dehydration and possible early interventions.

Methods Only healthy term/near-term inborn babies were included. They were examined on days four, seven and ten of life. Blood samples were collected on days four and ten of life, serum was separated and stored at $-20^{\circ} \mathrm{C}$ for subsequent analysis for sodium. Serum sodium was compared with weight loss and different risk factors were analysed for association with hypernatremia.

Results 184 healthy term/near-term neonates were included. Mean serum sodium was $149 \pm 6.0$ (135-172). Sodium levels were normal (135-145) in 47 (25.5\%) neonates; hypernatremia of varying severity was detected in 137 (74.5\%). 62 $(33.7 \%)$ neonates had serum sodium levels between 146 and 150, $62(33.7 \%)$ between 151 and 159, and $13(7 \%)$ had serum sodium $\geq 160$. By day 10 of life sodium levels had normalised in all except one, who was hospitalised on day 5 of life with hypernatremic dehydration. His day 4 serum sodium was subsequently found to be 172 . Association of different risk factors with hypernatremia is in the table 1 . Signs of dehydration were discernible in only nine patients and all of them had hypernatremia, however, most of the babies didn't have obvious dehydration signs.

Conclusion Mild to moderate hypernatremic dehydration is quite common in early neonatal period and adequate breastfeeding is an effective and safe intervention.
Abstract G207(P) Table 1 Comparison of variables between two groups

\begin{tabular}{llll}
\hline & $\begin{array}{l}\text { Hypernatremic } \\
\text { neonates }\end{array}$ & $\begin{array}{l}\text { Neonates with normal } \\
\text { sodium }\end{array}$ & $\begin{array}{l}\text { P- } \\
\text { value }\end{array}$ \\
\hline Maternal age & $30.1 \pm 3.4$ & $28.7 \pm 3.9$ & 0.07 \\
Birth wt & $3.09 \pm 0.46$ & $3.11 \pm 0.41$ & 0.77 \\
Symp/asymptomatic & $49 / 88$ & $7 / 40$ & 0.009 \\
Oliguria & 13 & 0 & 0.04 \\
Nipple problem & 3 & 0 & 0.57 \\
Decreased milk & 21 & 1 & 0.016 \\
production & & 0 & \\
Signs of dehydration & 9 & 2 & 0.11 \\
Wt loss $>10 \%$ & 13 & 12 & 0.36 \\
Daily wt loss $>2 \%$ & 47 & $20 / 27$ & 0.28 \\
Caesarean/Normal & $87 / 50$ & & 0.016 \\
Delivery & & $26 / 21$ & \\
first-born/later-born & $50 / 87$ & & 0.026 \\
\hline
\end{tabular}

\section{G208(P) NEONATAL CONGENITAL HEART BLOCK - MANAGEMENT AND OUTCOME ON CASES ADMITTED TO A REGIONAL NEONATAL INTENSIVE CARE UNIT}

I Sadasivam, S Kamupira. Department of Neonates, St. Mary's Hospital, Manchester Foundation Trust, Manchester, UK

\subsection{6/archdischild-2018-rcpch.203}

Aim Congenital heart block $(\mathrm{CHB})^{1,2}$ detected at or before birth is strongly associated with maternal autoimmune antibodies, anti - La and anti Ro. The majority of cases are diagnosed between 18-24th weeks of gestation. Most mothers carrying auto-immune antibodies are not aware until their child is diagnosed with CHB. Our aim was to review the presentation, management and outcome of neonates admitted with $\mathrm{CHB}$ to a regional neonatal intensive care unit (NICU).

Method We conducted a retrospective case notes review of all infants admitted with $\mathrm{CHB}$ to NICU over an 8 year period, $07 / 2009$ to $08 / 2017$.

Results 14 babies, 8 females and 6 males were admitted during the study period. 12 cases were diagnosed during the antenatal period and 2 cases postnatally (including undiagnosed $\mathrm{CHB}$ presenting with foetal bradycardia at 27 weeks). All 14 infants were born by caesarean section in view of foetal bradycardia (range 35-90 bpm). The median gestational age was 36 weeks(27-39 weeks) and the mean birth weight was $2442 \mathrm{~g}$ (1138 g-3360 g).The reasons of CHB in these 14 babies are explained as follows:

- 10 cases had maternal Anti-Ro and Anti-La antibodies (3 cases of Sjögren's syndrome, 2 cases of Systemic Lupus Eryhtematosus and 5 cases were asymptomatic).

- 3 cases associated with Congenital heart disease (1 congenitally corrected TGA, 1 Left atrial isomerism and 1 VSD,ASD,PDA).

- 1 case of Long QTc syndrome with $\mathrm{KCNH} 2$ genetic mutation

They were admitted to NICU and assessed with 12-lead and 24 hour ECG, echocardiography and electrolyte analysis (Potassium, calcium and Magnesium). 3 infants developed life threatening arrhythmias with pulseless ventricular tachycardia 